\title{
Comparison of the Efficiency and Safety of Non-viral Vector-Mediated Gene Transfer into a Wide Range of Human Cells
}

\author{
Eriko Uchida, ${ }^{*}$ Hiroyuki Mizuguchi, Akiko Ishit-Watabe, and Takao Hayakawa \\ Division of Biological Chemistry and Biologicals, National Institute of Health Sciences; 1-18-1 Kamiyoga, Setagaya-ku, \\ Tokyo 158-8501, Japan. Received January 30, 2002; accepted April 16, 2002
}

\begin{abstract}
Non-viral gene transfer into a wide range of human cells was examined in order to clarify the factors that affect the efficiency and safety of non-viral vectors and to optimize the conditions so that high efficiency and low toxicity could be achieved. Six non-viral vectors (Lipofectin, LipofectAMINE PLUS, SuperFect, Effectene, DMRIE-C and DOTAP) were used to transfect a mammalian expression plasmid pCMV $\beta$ into 16 types of human primary cells and cultured cell lines. Transfection efficiency was quantified using a galactosidase assay. Cytotoxic effects were measured by lactate dehydrogenase (LDH) assay and WST-8 assay. In serum-free conditions, LipofectAMINE PLUS, Effectene and SuperFect, on average, transfected DNA more successfully than Lipofectin, DMRIE-C, and DOTAP, although the levels of gene expression with these vectors varied remarkably in different cells. The most effective vector also differed depending on the cell type. Serum was found to inhibit gene transfer and reduce the cytotoxicity of all of these vectors except Effectene. The efficiency and toxicity of the non-viral vectors used depended on the type of vector, the DNA/vector ratio, the type of cell, and the presence of serum. These results provided useful information for the optimization of transfer conditions of these non-viral vectors.
\end{abstract}

Key words gene transfer; non-viral vector; transfection efficiency; cytotoxicity

Non-viral vectors for gene therapy, although less efficient for gene delivery, offer several advantages over viral vectors. Non-viral vectors are particularly suitable with respect to simplicity of use and ease of large-scale production, and they are relatively inexpensive to produce, easier to quality control, and generate little or no specific immune response. Nonviral DNA delivery has also become a powerful and popular research tool for elucidating gene structure, regulation, and function. Various types of synthetic vectors such as cationic lipids and polymers have been developed for gene transfer with high transfection efficiency. ${ }^{1-3)}$

It is necessary to evaluate the efficiency and safety of gene transfer with gene therapy vectors. Many factors may affect the efficacy and safety of non-viral vector-mediated gene transfer, including the structure, charge, and formulation of the vector, the preparation of DNA/vector complexes, ${ }^{4,5)}$ DNA/vector ratio, charge and size of complexes, ${ }^{6-8)}$ time of exposure, and interaction with serum and blood cells. ${ }^{9,10)}$ As optimal conditions might well differ for different cell types, careful optimization is required to evaluate the efficacy and safety of vectors for the target cells and target organs. ${ }^{11-14)}$

In this study, we compared the transfection efficiency and safety of commercially available non-viral vectors with a variety of human cells including primary cells, blood cell lines, and adherent cell lines. We also clarified important factors that affected the evaluation of these vectors. The transfection efficiency and cytotoxicity of all non-viral vectors used was dependent on the type of vector, vector concentration, presence of serum, and type of cell. These results also provided useful information for understanding the characteristics of each vector and selecting the most suitable vector for gene transfer into target cells.

\section{MATERIALS AND METHODS}

Cells The human cultured cell lines and primary cells listed below were used. HeLa, 293, A-172, CCD-14Br, HuH-
7, SBC-1, NB-1, K-562, HL60, U937 and IM-9 cells were obtained from the Health Science Research Resource Bank. Jurkat cell was obtained from the RIKEN cell bank. Human umbilical vein endothelial cells (HUVEC), human umbilical vein smooth muscle cells (HUVSMC), and human skin fibroblast cells (HSFB) from 10 donors were obtained from Technoclone (Wien, Austria). Human hepatocytes were purchased from Tissue Transformation Technologies (Edison, NJ). The media used for maintaining cells were as follows: Eagle's minimal essential medium (MEM) supplemented with $10 \%$ fetal calf serum (FCS) and non-essential amino acids (HeLa and CCD-14Br); Dulbecco's modified Eagle's medium (DMEM) containing 10\% FCS (A-172 and HuH-7); MEM supplemented with 10\% FCS (293); 45\% MEM and $45 \%$ RPMI 1640 medium supplemented with $10 \%$ FCS (NB1); RPMI 1640 medium supplemented with $10 \%$ FCS (SBC1, K-562, U937, HL60, IM-9 and Jurkat cells); and 199 medium supplemented with $20 \%$ FBS containing $5 \mathrm{U} / \mathrm{ml}$ of heparin and $15 \mu \mathrm{g} / \mathrm{ml}$ Endothelial Cell Growth Supplement (Technoclone) on collagen type I-coated dishes (HUVEC, HUVSMC and HSFB). In the case of human hepatocytes, frozen cells were thawed and plated on collagen-type-Icoated 96-well plates the day before the experiments in Hepatocyte Culture Medium (Clonetics Co., Walkersville, MD, U.S.A.).

Non-viral Vectors Six commercially available transfection reagents were used as non-viral vectors: Lipofectin, LipofectAMINE PLUS, and DMRIE-C (GIBCO-BRL, Gaithersburg, MD), SuperFect and Effectene (QIAGEN, Hilden, Germany), and DOTAP (Boehringer Mannheim, Mannheim, Germany). The composition of each of the vectors was as follows: Lipofectin ${ }^{15)}: 1: 1(\mathrm{w} / \mathrm{w})$ liposome formulation of the cationic lipid $N$-[1-(2,3-dioleyloxy)propyl]- $N, N, N-$ trimethylammonium chloride (DOTMA) and dioleoyl phosphatidylethanolamine (DOPE) $(1 \mathrm{mg} / \mathrm{ml})$; LipofectAMINE PLUS: $3: 1(\mathrm{w} / \mathrm{w})$ liposome formulation of the polycationic lipid 2,3-diolexyloxy- $N$-[2(Spermine carboxamido)ethyl]- 
$N, N$-dimethyl-1-propanammonium trifluoroacetate (DOSPA) and DOPE $2 \mathrm{mg} / \mathrm{ml}$ ) with PLUS reagent for pre-complexing DNA; SuperFect ${ }^{16)}$ : cationic polymer polyamidoamine dendrimer $(3 \mathrm{mg} / \mathrm{ml})$; Effectene: $1 \mathrm{mg} / \mathrm{ml}$ non-liposomal lipid with DNA condensation reagent Enhancer ( $1 \mathrm{mg} / \mathrm{ml})$; DMRIE$\mathrm{C}^{17)}: 1: 1(\mathrm{~mol} / \mathrm{mol})$ liposome formulation of the cationic lipid DMRIE and cholesterol $(2 \mathrm{mg} / \mathrm{ml})$; DOTAP: liposome formulation of the cationic lipid $N$-[1-(2,3-dioleoyloxy)propyl]- $N, N, N$-trimethylammonium methylsulfate (DOTAP; $1 \mathrm{mg} / \mathrm{ml}$ ).

Preparation of DNA/Vector Complex $\beta$-Galactosidase (LacZ) expression plasmid pCMV $\beta$ (Clontech, Palo Alto, CA, U.S.A.) was amplified in Escherichia coli DH5 $\alpha$ and purified with the EndoFree Plasmid Maxi kit (QIAGEN). For each transfection, $\mathrm{pCMV} \beta(0.1 \mu \mathrm{g} / \mathrm{each}$ well of a 96 -well plate) was mixed with $0.25,0.5,1$, or $2 \mu \mathrm{g}$ of each vector (DNA: vector ratio $(\mathrm{w} / \mathrm{w})=1: 2.5,1: 5,1: 10,1: 20)$. In the case of LipofectAMINE PLUS and Effectene, plasmid DNA $(0.1 \mu \mathrm{g})$ was mixed with $1 \mu \mathrm{l}$ of PLUS reagent and $0.8 \mu \mathrm{l}$ of Enhancer reagent before being mixed with each vector, respectively. DNA, vectors and DNA condensation reagents were mixed in Opti-MEM I (GIBCO-BRL; Lipofectin, LipofectAMINE PLUS, SuperFect, DMRIE-C and DOTAP), or in buffer EC (Effectene) and were incubated for optimal times following the manufacturer's protocols to make the DNA/vector complexes. Opti-MEM I was then added to prepare $50 \mu \mathrm{l} /$ well solution for each transfer.

Transfection Conditions Adherent cells were plated at a density of 5000 cells per well of a 96-well plate in growth medium the day before transfection and were cultured for $20-24 \mathrm{~h}$. Cells were washed once with Opti-MEM I, and then $50 \mu \mathrm{l}$ of Opti-MEM I with or without $20 \%$ FCS was added to each well. In the case of the blood cell lines (K-562, HL60, U937, Jurkat and IM-9), 25000 cells were suspended in $50 \mu \mathrm{l}$ Opti-MEM I medium with or without $20 \%$ FCS and plated in each well of a 96-well plate just before transfection. DNA/vector complexes were then added to each well $\left(50 \mu \mathrm{l} /\right.$ well) and incubated with cells for $1 \mathrm{~h}$ at $37^{\circ} \mathrm{C}$. The supernatants were then removed and $100 \mu \mathrm{l}$ of the growth medium of each cell were added to each well and cultured for an additional $24 \mathrm{~h}$ at $37^{\circ} \mathrm{C}$ in $5 \% \mathrm{CO}_{2}$.

Reporter Gene Assay Transfection efficiency was measured by the expression of $\beta$-galactosidase reporter gene at $24 \mathrm{~h}$ post transfection. Cells were washed once with phosphate buffered saline (PBS), and $\beta$-galactosidase activity was quantified by the chemiluminescent reporter gene assay system Galacto-Star (Tropix Inc., Bedford, MA, U.S.A.) according to the instruction manual. The chemiluminescent of each cell lysate was read on the ARVO 1420 multilabel counter (Perkin Elmer, Boston, MA, U.S.A.). Galactosidase-luminescent activity was expressed as relative light units (RLU) per well of a 96-well plate.

X-Gal Staining Transfection efficiency was also monitored by a 5-bromo-4-chloro-3-indolyl- $\beta$-D-galactpyranoside (X-gal) staining assay at $24 \mathrm{~h}$ post-transfection. Cells were fixed with $1 \%$ glutaraldehyde for $10 \mathrm{~min}$, washed twice with PBS, and stained with $1 \mathrm{mg} / \mathrm{ml} \mathrm{X}$-gal in a solution of $1 \mathrm{~mm}$ $\mathrm{MgCl}_{2}, 5 \mathrm{mM} \mathrm{K} \mathrm{K}_{3} \mathrm{Fe}(\mathrm{CN})_{6}$, and $5 \mathrm{mM} \mathrm{K} \mathrm{K}_{4} \mathrm{Fe}(\mathrm{CN})_{6}$ for $2 \mathrm{~h}$ to $24 \mathrm{~h}$. The percentages of lacZ-positive cells were determined by counting at least 1000 cells by light microscopy.

Lactate Dehydrogenase (LDH) Assay The toxicity of the vector-DNA complexes to the cellular membrane was measured as the leakage of LDH from the cells. After incubation of the cells with DNA/vector complexes for $1 \mathrm{~h}$, the supernatant of each well was transferred into another 96-well plate, and LDH activity was measured using a commercially available kit (LDH Cytotoxic Test Wako; WAKO, Osaka, Japan). Plates were read on a microplate reader EL340 (BIOTEK Instruments, Winooski, VT) at a wavelength of $560 \mathrm{~nm}$.

Cell Viability Cytotoxicity was also assessed as cell viability using 4-[3-(2-methoxy-4-nitrophenyl)-2-(4-nitrophenyl)-2H-5-tetrazolio]-1,3-benzene disulfonate sodium salt (WST-8), a novel tetrazolium salt, using a commercially available kit (TetraColor ONE cell proliferation assay system; Seikagaku Co., Tokyo, Japan). After $24 \mathrm{~h}$ of transfection, TetraColor ONE $(10 \mu \mathrm{l})$ was added to each well and incubated for $4 \mathrm{~h}$ at $37^{\circ} \mathrm{C}$. Plates were read on microplate reader EL340 using a wavelength of $450 \mathrm{~nm}$ in comparison with $630 \mathrm{~nm}$.

\section{RESULTS}

HeLa Cells First, we compared the efficiency and toxic-
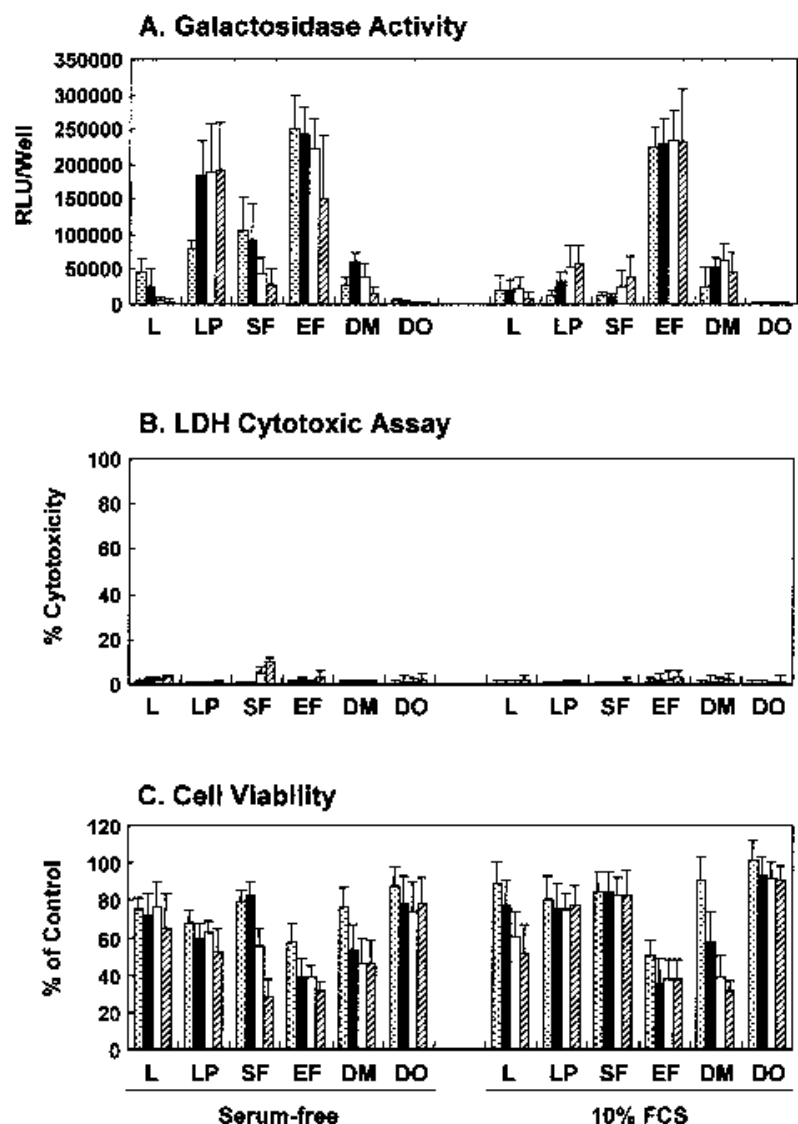

DNA:vector ratio (whi) $\quad 1: 2.5 \quad \square 1 \div 5 \quad 01: 10 \quad$ a $1: 20$

Fig. 1. Comparison of Transfection Efficiency and Toxicity of Non-viral Vectors on HeLa Cells

HeLa cells $(5000$ cells per well) were seeded in a 96 -well plate $24 \mathrm{~h}$ before transfection, and $\mathrm{pCMV} \beta$ were transfected into cells with Lipofectin (L), LipofectAMINE PLUS (LP), SuperFect (SF), Effectene (EF), DMRIE-C (DM) or DOTAP (DO) as described in Materials and Methods. (A) Galactosidase gene expression was quantified at $24 \mathrm{~h}$ after transfection; (B) Cytotoxicity determined by LDH release was monitored at $1 \mathrm{~h}$ after transfection; (C) Cell viability was examined at $24 \mathrm{~h}$ after transfection as described in Materials and Methods. Data represent the mean of 5 independent experiments \pm standard deviation (S.D.). 
Table 1. LacZ Expression of Various Non-viral Vectors Evaluated by X-Gal Staining

\begin{tabular}{|c|c|c|c|c|c|c|}
\hline \multirow{2}{*}{ Cells } & \multicolumn{6}{|c|}{$\%$ LacZ positive cells (DNA: vector ratio $(w / w)=1: 5$ ) } \\
\hline & Lipofectin & $\begin{array}{l}\text { LipofectAMINE } \\
\text { PLUS }\end{array}$ & SuperFect & Effectene & DMRIE-C & DOTAP \\
\hline \multicolumn{7}{|l|}{ Serum free } \\
\hline HeLa & 2.0 & 33.1 & 13.7 & 41.2 & 22.2 & 1.0 \\
\hline HUVEC & 0.9 & 9.3 & 10.9 & 5.1 & 4.4 & 0.2 \\
\hline HUVSMC & 0.0 & 0.4 & 0.0 & 1.1 & 0.1 & 0.0 \\
\hline HSFB & 0.0 & 1.2 & 1.0 & 1.6 & 0.8 & 0.2 \\
\hline Hepatocyte & 0.0 & 0.0 & 0.0 & 0.1 & 0.1 & 0.0 \\
\hline \multicolumn{7}{|l|}{$10 \%$ FCS } \\
\hline HeLa & 1.4 & 5.0 & 2.2 & 35.6 & 11.7 & 0.5 \\
\hline HUVEC & 0.0 & 0.0 & 3.8 & 4.2 & 4.4 & 0.2 \\
\hline HUVSMC & 0.0 & 0.0 & 0.0 & 0.2 & 0.0 & 0.0 \\
\hline HSFB & 0.0 & 0.0 & 0.3 & 0.5 & 0.0 & 0.0 \\
\hline Hepatocyte & 0.0 & 0.0 & 0.0 & 0.4 & 0.1 & 0.0 \\
\hline
\end{tabular}

ity of non-viral vectors on HeLa cells (carcinomas of the cervix), a commonly used cell line for transfection experiments (Fig. 1). In serum-free conditions, LipofectAMINE PLUS and Effectene showed strong gene expression compared to Lipofectin, SuperFect, DMRIE-C and DOTAP (Fig. 1A). Galactosidase activity reached more than 200000 RLU/well. When gene expression was evaluated by X-gal staining, more than $30 \%$ of the cells were found to be positive for $\beta$-galactosidase activity by LipofectAMINE PLUS and Effectene (Table 1). The transfection efficiency of Effectene did not change even in the presence of $10 \% \mathrm{FCS}$, and gene expression by LipofectAMINE PLUS decreased to less than half of that under serum-free conditions.

The cytotoxic effects of DNA/vector complexes quantified by LDH assay are shown in Fig. 1B. The maximum cytotoxic effect was $9.6 \%$ when cells were incubated with DNA/SuperFect complexes (DNA: vector ratio $=1: 20$ ) in serum-free conditions. The toxicity of transfection in other conditions and other vectors was not so significant, although a higher vector ratio caused higher toxicity.

The cytotoxic effects of gene transfer were also analyzed by determining cell viability at $24 \mathrm{~h}$ post-transfection using WST-8 assay (Fig. 1C). In serum-free conditions, cell viability was decreased in a vector-ratio-dependent manner. Particularly in the case of SuperFect and Effectene, cell viability at the highest vector ratio $(1: 20)$ was decreased to below $50 \%$. When gene transfer was performed in the presence of $10 \%$ FCS, the decrease of cell viability induced by LipofectAMINE PLUS and SuperFect was repressed. However, strong damage to cell viability was still observed when Effectene was used for the gene transfer.

Human Primary Cells Primary cells are a useful tool for the evaluation of gene therapy vectors for human use. We tested the transfection efficiency and toxicity of each vector in human primary cells such as HUVEC, HUVSMC, HSFB and human hepatocytes (Fig. 2). In the case of HUVEC cells, strong gene expressions were obtained with LipofectAMINE PLUS, SuperFect and Effectene when the transfection was done in the absence of serum (Fig. 2A). The level of gene expression was close to those achieved in HeLa cells. In HUVSMC and HSFB cells, though these vectors also caused higher gene expression than other vectors, the expression levels were only about $5-10 \%$ of those achieved in HUVEC cells. In these cells, the percentages of X-gal positive cells were very low (a few positive cells in a well) and the extent of staining was also weak (Table 1). In these cells, serum strongly inhibited gene expression. In the case of hepatocytes, only Effectene successfully transferred genes both in the presence and absence of serum, and the level of gene expression was about $40 \%$ of that of HUVEC. Transfection efficiency was completely different among primary cells.

As for toxicity evaluated by cell viability, the differences among cells were very small and the dose-dependent cytotoxicity was similar to that in HeLa cells (Fig. 2B). The toxicity of DNA/vector complexes evaluated by LDH assay was not highly significant in HUVEC, HUVSMC, and HSFB cells (Table 2). On the other hand, in the case of human hepatocytes, $31.5 \%$ and $17.7 \%$ cytotoxicity was observed when transfection was done with SuperFect and Effectene (DNA: vector ratio $=1: 20$ ), respectively.

Human Blood Cell Lines Blood cells are an important target for gene therapy and molecular biology. We examined the transfection efficiency and cytotoxicity of each nonviral vector for five types of typical cultured human blood cell lines: K-562 (erythroblastic leukemia), HL60 (acute promyelotic leukemia), U937 (monoblastic leukemia), Jurkat (T-lymphoma) and IM-9 (B-lymphoblasts) cells. Successful transfection in K-562 cells was achieved with LipofectAMINE PLUS in serum-free conditions (Fig. 3A). The same vector caused the highest gene expression in HL60 cells; however, the level of gene expression was only 1/300 of that obtained in K-562 cells. In U937, Jurkat, and IM-9 cells, although the most effective gene expression was achieved with SuperFect, LipofectAMINE PLUS or SuperFect, and Effectene, respectively, the levels of gene expression were $1 / 10$ or lower than those of the K-562 cells transfected with LipofectAMINE PLUS. The transfection efficiencies of these conditions were reduced by the presence of $10 \%$ FCS.

The susceptibility of cultured blood cells to non-viral vectors was higher than that of HeLa cells and primary cells when the gene transfer was done in the absence of serum (Fig. 3B). The highest DNA: vector ratio $(1: 20)$ caused remarkable damage to cells, and cell viability decreased below $10 \%$ in most cases. On the other hand, the toxicity of DNA/ vector complexes was strongly inhibited by the addition of serum during transfection. The LDH assay also demonstrated 

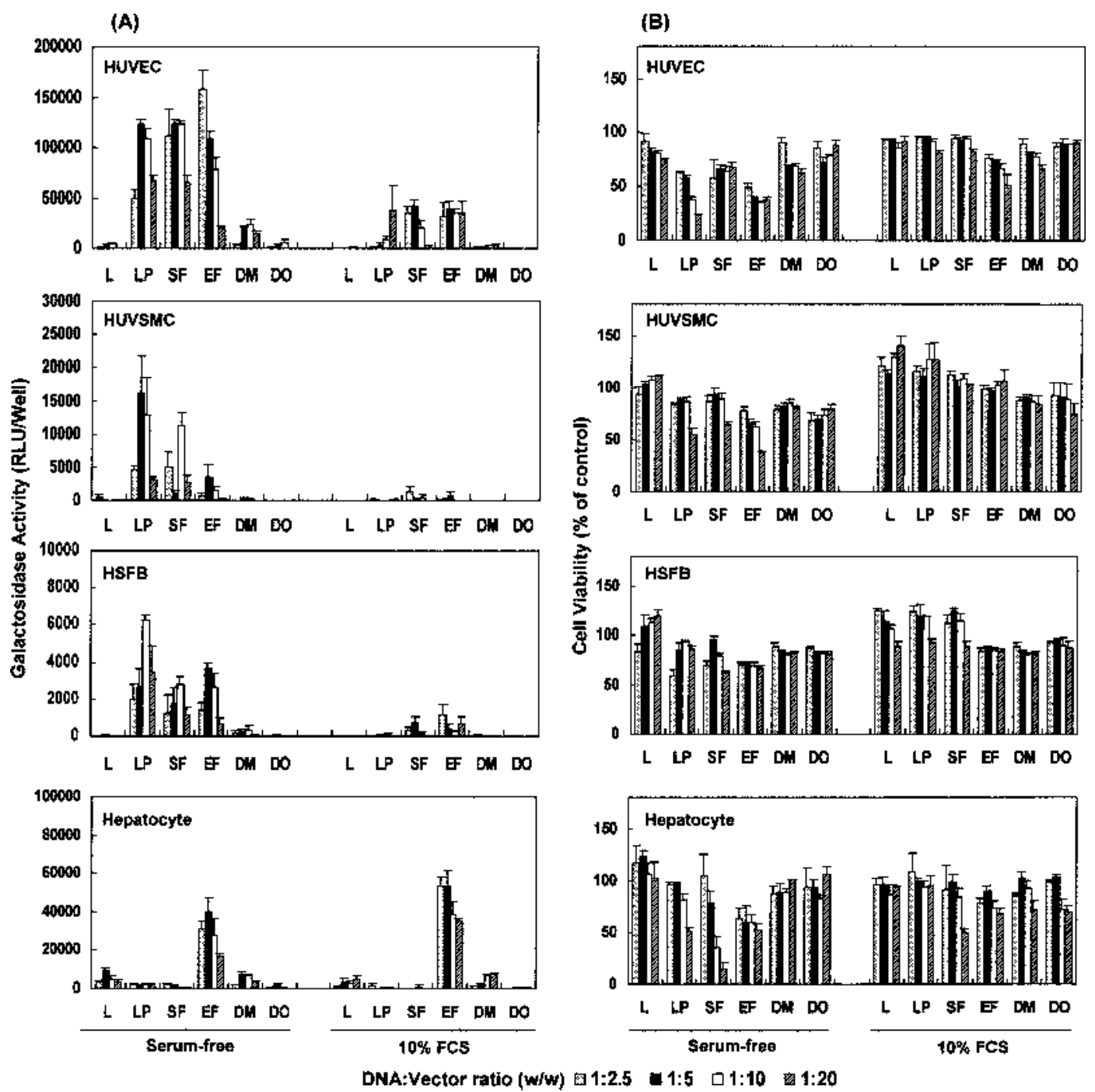

Fig. 2. Comparison of Transfection Efficiency and Toxicity of Non-viral Vectors on Human Primary Cells

HUVEC, HUVSMC, HSFB and human hepatocytes (5000 cells per well) were seeded in 96-well plates $24 \mathrm{~h}$ before transfection and pCMV $\beta$ were transfected into cells as described in Fig. 1. (A) Galactosidase gene expression level and (B) Cell viability at $24 \mathrm{~h}$ after transfection were determined. Data represent the mean \pm S.D. $(n=3)$.

Table 2. Cytotoxicity of Various Non-viral Vectors Evaluated by LDH Assay

$\%$ Cytotoxicity (Serum free, DNA: vector ratio $(\mathrm{w} / \mathrm{w})=1: 20)$

\begin{tabular}{|c|c|c|c|c|c|c|}
\hline Cells & Lipofectin & $\begin{array}{l}\text { LipofectAMINE } \\
\text { PLUS }\end{array}$ & SuperFect & Effectene & DMRIE-C & DOTAP \\
\hline HeLa & $3.3 \pm 1.1$ & $1.2 \pm 0.3$ & $9.6 \pm 2.8$ & $2.9 \pm 3.1$ & $1.4 \pm 0.6$ & $2.4 \pm 2.2$ \\
\hline HUVEC & $2.5 \pm 1.5$ & $1.6 \pm 2.8$ & $0.8 \pm 1.1$ & $2.6 \pm 1.1$ & $0.8 \pm 2.1$ & $0.1 \pm 1.5$ \\
\hline HUVSMC & $2.5 \pm 0.9$ & $0.8 \pm 1.3$ & $0.8 \pm 0.5$ & $2.0 \pm 0.5$ & $1.3 \pm 1.3$ & $1.0 \pm 0.8$ \\
\hline HSFB & $2.0 \pm 1.8$ & $1.0 \pm 1.4$ & $0.3 \pm 0.5$ & $1.7 \pm 1.2$ & $1.4 \pm 1.6$ & $0.5 \pm 0.7$ \\
\hline Hepatocyte & $0.9 \pm 4.3$ & $5.0 \pm 4.2$ & $31.5 \pm 0.1$ & $17.7 \pm 4.3$ & $0.0 \pm 1.9$ & $0.0 \pm 6.2$ \\
\hline K-562 & $2.8 \pm 0.4$ & $5.4 \pm 0.8$ & $18.0 \pm 0.7$ & $6.5 \pm 0.6$ & $2.4 \pm 0.7$ & $3.5 \pm 0.7$ \\
\hline HL60 & $3.9 \pm 3.2$ & $15.0 \pm 0.6$ & $43.4 \pm 3.9$ & $18.7 \pm 8.8$ & $14.9 \pm 0.4$ & $4.5 \pm 7.6$ \\
\hline U937 & $6.0 \pm 0.5$ & $34.2 \pm 1.7$ & $75.7 \pm 7.3$ & $32.3 \pm 3.6$ & $6.5 \pm 1.9$ & $18.5 \pm 0.5$ \\
\hline Jurkat & $2.2 \pm 1.0$ & $8.1 \pm 0.7$ & $43.1 \pm 1.4$ & $12.4 \pm 1.3$ & $2.4 \pm 0.8$ & $4.6 \pm 0.6$ \\
\hline IM-9 & $13.9 \pm 3.9$ & $15.7 \pm 3.0$ & $29.0 \pm 1.2$ & $11.9 \pm 0.6$ & $5.3 \pm 1.7$ & $7.5 \pm 0.3$ \\
\hline 293 & $7.1 \pm 2.4$ & $2.7 \pm 2.2$ & $2.4 \pm 1.2$ & $3.0 \pm 1.8$ & $3.1 \pm 2.4$ & $0.9 \pm 1.0$ \\
\hline CCD-14Br & $1.4 \pm 0.2$ & $1.2 \pm 0.5$ & $0.9 \pm 0.5$ & $0.4 \pm 0.5$ & $0.3 \pm 0.7$ & $0.4 \pm 0.5$ \\
\hline $\mathrm{HuH}-7$ & $3.4 \pm 1.9$ & $3.6 \pm 2.6$ & $3.2 \pm 1.0$ & $13.4 \pm 1.9$ & $8.6 \pm 4.0$ & $8.8 \pm 1.6$ \\
\hline A-172 & $5.2 \pm 1.0$ & $1.1 \pm 1.4$ & $1.3 \pm 0.2$ & $3.7 \pm 3.6$ & $2.0 \pm 1.3$ & $1.1 \pm 1.2$ \\
\hline NB-1 & $6.2 \pm 2.5$ & $3.2 \pm 2.9$ & $17.9 \pm 3.5$ & $6.3 \pm 3.2$ & $1.2 \pm 1.1$ & $1.4 \pm 1.1$ \\
\hline
\end{tabular}



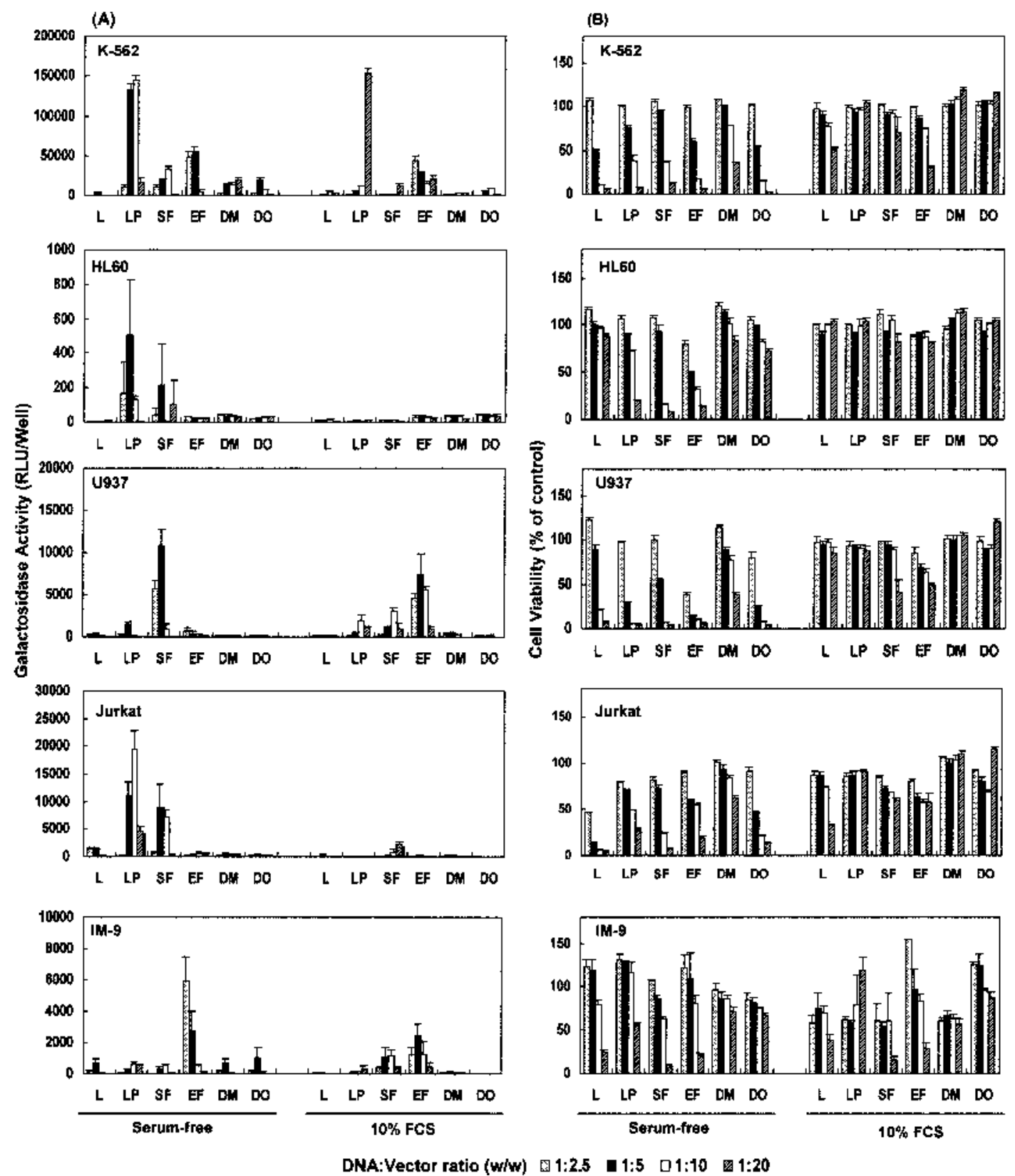

Fig. 3. Comparison of Transfection Efficiency and Toxicity of Non-viral Vectors on Human Blood Cell Lines

K-562, HL60, U937, Jurkat, and IM-9 cells (25000 cells in each well of 96-well plates) were seeded before transfection, and pCMV $\beta$ were transfected intoasinto cells as described in Fig. 1. (A) Galactosidase gene expression and (B) Cell viability at $24 \mathrm{~h}$ after transfection were determined as described in Materials and Methods. Data represent the mean \pm S.D. $(n=3)$.

the high sensitivity of blood cell lines to the toxicity of nonviral vectors (Table 2). Particularly, SuperFect in serum-free conditions showed the strongest toxicity.

Human Cultured Cell Lines Finally, we studied the transfection efficiency and toxicity to human cultured cell lines commonly used for transfection experiments and to cells derived from major target organs of gene therapy. The selected cell lines were as follows: 293 (embryonic kidney cells), HuH-7 (hepatoma), CCD-14Br (bronchus fibroblast), SBC-1 (lung small cell carcinoma), A-172 (glioblastoma) and NB-1 (neuroblastoma) cells. In the absence of serum, 293 and HuH-7 cells showed strong gene expression with LipofectAMINE PLUS and Effectene (Fig. 4A). In contrast, the gene expressions of CCD-14Br, SBC- 1 and A-172 cells were 10 -fold lower, and that of NB-1 cells was 100 -fold lower than those obtained in 293 and HuH-7 cells. Effectene induced the best gene expression in these cells. Moreover, even in the presence of serum, Effectene induced gene expression at the same level as in serum-free conditions, although it showed strong cytotoxicity even in the presence of serum (Fig. 4B). LDH assay revealed that NB-1 cells (by SuperFect) and HuH-7 cells (by Effectene) received more than $10 \%$ toxicity, although other cells and conditions demonstrated only weak toxicity (Table 2 ).

\section{DISCUSSION}

In this study, we performed a comparative analysis of the transfection efficiency and cytotoxicity of six non-viral vectors for gene transfer to a wide range of human cells. The 

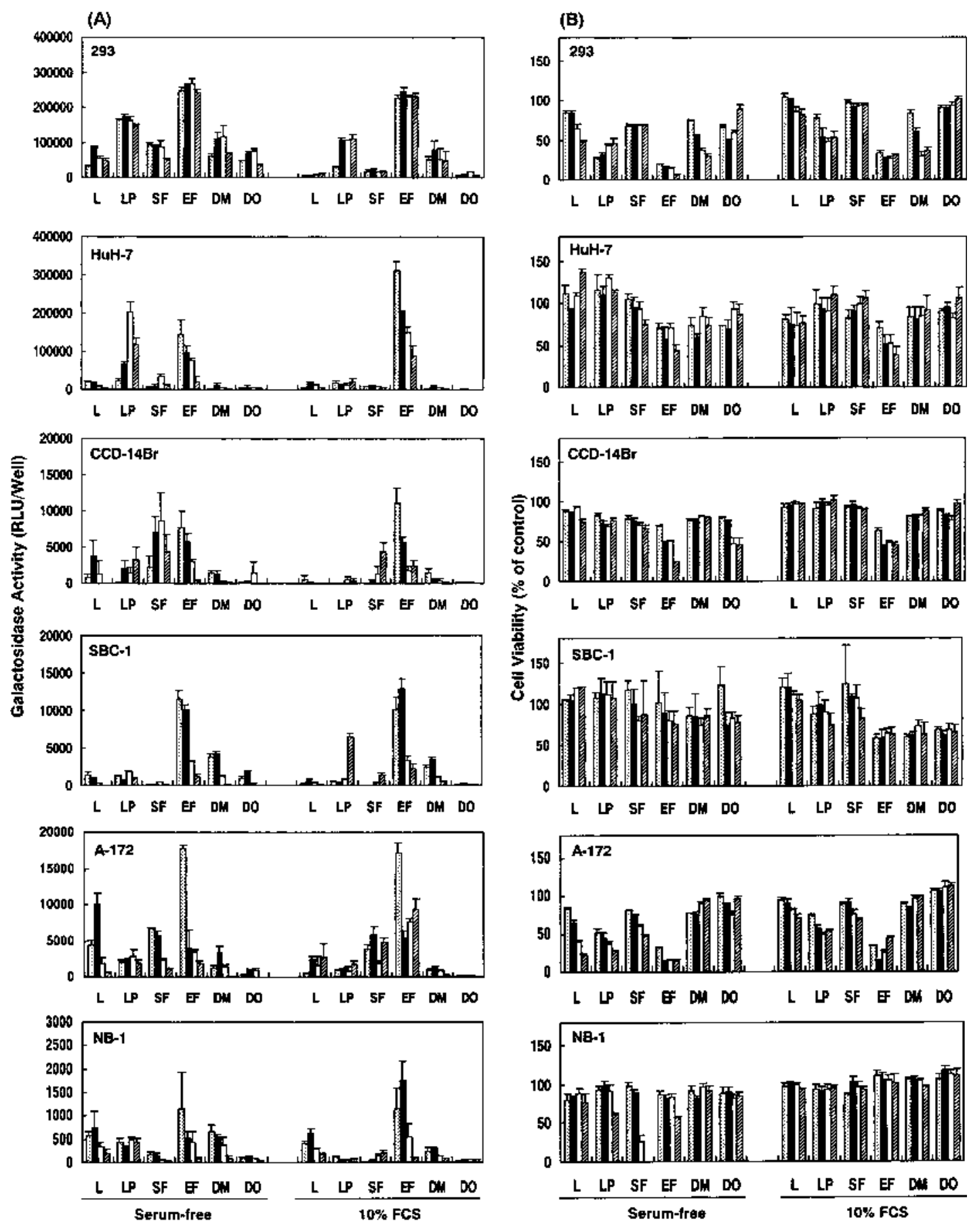

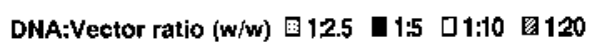

Fig. 4. Comparison of Transfection Efficiency and Toxicity of Non-viral Vectors on Human Cultured Cell Lines

293, HuH-7, CCD-14Br, SBC-1, A-172, and NB-1 cells (5000 cells per well in 96-well plates) were seeded the day before transfection, and pCMV $\beta$ were transfected into cells as described in Fig. 1. (A) Galactosidase gene expression level and (B) Cell viability at $24 \mathrm{~h}$ after transfection were determined as described in Materials and Methods. Data represent mean \pm S.D. $(n=3)$.

data clearly showed that the safety and efficiency of the gene transfer depended on the vector used. In serum-free conditions, LipofectAMINE PLUS, Effectene, and in some cases SuperFect elicited higher gene expression than Lipofectin, DMRIE-C, and DOTAP in many of the cell types tested. In the presence of $10 \%$ FCS, Effectene was the most efficient vector for most cells. LipofectAMINE PLUS contains a multivalent cationic lipid with 5 potentially charged amine groups. Polyamidoamine (PAMAM) dendrimers such as
SuperFect are a class of highly branched polycationic polymers. ${ }^{2)}$ In contrast, Lipofectin, DMRIE-C and DOTAP are monovalent lipids. Our data corresponded with a report that found that multivalent lipids exhibited a higher transfection efficiency than monovalent lipid-containing liposomes. ${ }^{18)}$ LipofectAMINE PLUS and Effectene contain a DNA-compacting reagent in addition to cationic lipids, although their compositions are not avairable to the public. DNA compacting agents are reported to be effective for enhancing gene 
transfer and the acquisition of serum resistance. ${ }^{19,20)}$ In addition to the difference in the charges of the vectors, the DNA compacting reagents used for transfection with LipofectAMINE PLUS and Effectene may play a major role in the high transfection efficiency of these vectors.

These results described here also revealed that the most effective vector varied depending on the cells, and that the level of gene expression also exhibited great differences among the cells. These findings suggest that the major factor that determined the level of gene expression was the cell type. Among the cells used in this study, HeLa, HUVEC, K562, 293 and $\mathrm{HuH}-7$ cells exhibited 10 to 100 times higher gene expression than did HL60, IM-9, HSFB and NB-1 cells. It has been found that cells with low plasmid uptake activity may demonstrate a low level of gene expression. ${ }^{21)}$ The efficiency of plasmid transport from the cytoplasm to the nucleus may be one of the reasons for the differences in the level of gene expression among cells. ${ }^{22)}$ Cell mitosis plays an important role in transgene expression that is delivered by non-viral vectors. ${ }^{23-25)}$ Differences in these cell characteristics might explain the differences in the level of gene expression among the cells observed in this study.

It is important to estimate the cytotoxicity of DNA/vector complexes in order to evaluate gene transfer vectors. We studied cytotoxicity using two assays, LDH assay and cell viability, and there were differences between these two assays. LDH assay is a method of measuring cell toxicity from the damage to cell membranes ${ }^{26)}$ and is used as a toxicity assay for gene therapy vectors. ${ }^{27,28)} \mathrm{LDH}$ assay was reported to be a sensitive assay in measuring the early damage to cell membranes. ${ }^{28)}$ However, in all conditions and all cells tested, the cytotoxic effect of gene transfer as assessed by cell viability at $24 \mathrm{~h}$ post-transfection was higher than that quantified by LDH assay at $1 \mathrm{~h}$ post-transfection. These results suggested that the cytotoxicity of DNA/vector complexes occurs not only through an acute toxic effect on the cell membrane but also through the uptake of DNA/vector complexes into cells and the following gene expression. Cytotoxic studies also demonstrated that blood cell lines and hepatocytes were more susceptible to DNA/vector-complex-mediated cytotoxicity than were other cells. Thus, careful optimization is required when these cells are chosen as target cells.

Many cationic non-viral vectors are known to be sensitive to serum. Our data showed that the transfection efficiency of the non-viral vectors tested is sensitive to serum except in the case of Effectene. In addition, the cytotoxicity of these vectors is also reduced by the addition of serum. In the case of Effectene, however, the transfection efficiency and cytotoxic effects were serum-independent. The inhibitory effect of serum on the transfection efficiency is a major obstacle for the in vivo use of non-viral vectors as DNA delivery systems. It has been reported that there is a discrepancy between optimal in vitro and in vivo transfection efficiencies, ${ }^{29)}$ and one of the reasons for this is the effect of serum. In order to evaluate gene therapy vectors for in vivo human use, it might be useful to examine the efficiency and safety of vectors in the presence of human serum.

Several reports have demonstrated the optimization of non-viral gene transfer to individual cells. ${ }^{11-14)}$ However, there is no report that compares the effects of several commercially available vectors on a wide range of human cells. Our results clearly demonstrated the characteristics of each vector and cell tested, and provided useful information for the optimization of transfection conditions in order to minimize toxicity and maximize transgene expression.

Acknowledgements This work was supported by a grant from the Ministry of Health and Welfare of Japan.

\section{REFERENCES}

1) Li S., Huang L., Gene Ther., 7, 31-34 (2000).

2) Luo D., Saltzman W. M., Nat. Biotechnol., 18, 33-37 (2000).

3) Nishikawa M., Huang L., Hum. Gene Ther, 12, 861-870 (2001).

4) Kichler A., Zauner W., Ogris M., Wagner E., Gene Ther, 5, 855-860 (1998).

5) Yang J. P., Huang L., Gene Ther., 5, 380-387 (1998).

6) Ross P. C., Hui S. W., Gene Ther, 6, 651-659 (1999).

7) Son K. K., Patel D. H., Tkach D., Park A., Biochim. Biophys. Acta, 1466, $11-15$ (2000).

8) Sakurai F., Inoue R., Nishino Y., Okuda A., Matsumoto O., Taga T., Yamashita F., Takakura Y., Hashida M., J. Control. Release, 66, 255269 (2000).

9) Escriou V., Ciolina C., Lacroix F., Byk G., Scherman D., Wils P., Biochim. Biophys. Acta, 1368, 276-288 (1998).

10) Sakurai F., Nishioka T., Saito H., Baba T., Okuda A., Matsumoto O., Taga T., Yamashita F., Takakura Y., Hashida M., Gene Ther., 8, 677686 (2001).

11) Abul-Hassan K., Walmsley R., Boulton M., Curr. Eye Res., 20, 361366 (2000).

12) Armeanu S., Pelisek J., Krausz E., Fuchs A., Groth D., Curth R., Keil O., Quilici J., Rolland P. H., Reszka R., Nikol S., Mol. Ther., 1, 366375 (2000).

13) Peters M. T., Brigham K. L., King G. A., Meyrick B. O., Gao X., Stecenko A. A., Exp. Lung Res., 25, 183-197 (1999).

14) Dodds E., Dunckley M. G., Naujoks K., Michaelis U., Dickson G., Gene Ther, 5, 542-551 (1998)

15) Felgner P. L., Gadek T. R., Holm M., Roman R., Chan H. W., Wenz M., Northrop J. P., Ringold G. M., Danielsen M., Proc. Natl. Acad. Sci. U.S.A., 84, 7413-7417 (1987).

16) Hudde T., Rayner S. A., Comer R. M., Weber M., Isaacs J. D., Waldmann H., Larkin D. F., George A. J., Gene Ther., 6, 939-943 (1999).

17) Felgner J. H., Kumar R., Sridhar C. N., Wheeler C. J., Tsai Y. J., Border R., Ramsey P., Martin M., Felgner P. L., J. Biol. Chem., 269, 2550-2561 (1994).

18) Behr J. P., Demeneix B., Loeffler J. P., Perez-Mutul J., Proc. Natl. Acad. Sci. U.S.A., 86, 6982-6986 (1989).

19) Abe A., Miyanohara A., Friedmann T., Gene Ther., 5, 708-711 (1998).

20) Schwartz B., Ivanov M. A., Pitard B., Escriou V., Rangara R., Byk G., Wils P., Crouzet J., Scherman D., Gene Ther., 6, 282-292 (1999).

21) Matsui H., Johnson L. G., Randell S. H., Boucher R. C., J. Biol. Chem., 272, 1117-1126 (1997).

22) James M. B., Giorgio T. D., Mol. Ther, 1, 339-346 (2000).

23) Tseng W. C., Haselton F. R., Giorgio T. D., Biochim. Biophys. Acta, 1445, 53-64 (1999).

24) Mortimer I., Tam P., MacLachlan I., Graham R. W., Saravolac E. G., Joshi P. B., Gene Ther, 6, 403-411 (1999).

25) Brunner S., Sauer T., Carotta S., Cotten M., Saltik M., Wagner E., Gene Ther, 7, 401-407 (2000).

26) Heeg K., Reimann J., Kabelitz D., Hardt C., Wagner H., J. Immunol. Methods, 77, 237-246 (1985).

27) Fischer D., Bieber T., Li Y., Elsässer H. P., Kissel T., Pharm. Res., 16, 1273-1279 (1999).

28) Lappalainen K., Jääskeläinen I., Syrjänen K., Urtti A., Syrjänen S., Pharm. Res., 11, 1127-1131 (1994).

29) Song Y. K., Liu F., Chu S., Liu D., Hum. Gene Ther., 8, 1585-1594 (1997). 